\title{
Chemical composition of fenugreek hay leaves
}

\author{
Vira Obolkina1, Tamara Nosenko, \\ Olha Dzyhar ${ }^{1}$, Dzhamal Rakhmetov ${ }^{2}$
}

\author{
1- National University of Food Technologies, Kyiv, Ukraine \\ 2 - National botanical garden after M.M. Gryshko of National Academy of Sciences \\ named, Kyiv, Ukraine
}

\begin{tabular}{l} 
Keywords: \\
Fenugreek hay \\
Leaves \\
Spices \\
Aromatic \\
Phenolic \\
\hline
\end{tabular}

Article history:

Received

01.06 .2018

Received in

revised form

29.08.2018

Accepted

28.09.2018

\section{Corresponding author:}

Olha Dzyhar

E-mail:

olgadzygar@

gmail.com

DOI:

$10.24263 / 2304-$ 974X-2018-7-3-5

\section{Abstract}

Introduction. It was researched the chemical composition of fenugreek hay leaves which is a source of biologically active substances and used as spice-aromatic raw materials for the confectionery products.

Materials and methods. The chemical composition of fenugreek hay leaves were studied by ultra high-speed high performance liquid chromatography, spectrophotometry and gas chromatography with mass-selective detection. To investigate the composition of leaves extract aglycones acidic hydrolysis was used. After hydrolysis aglycones were extracted by ethylacetate and extracts were used for chromatography. To identify component composition the derivatization method was used.

Results and discussion. The presence of phenolic compounds, phenolcarbonic acids, chlorophylls, trigonoline alkaloids, which have a high antioxidant potential, was confirmed in the chemical composition of fenugreek leaves. It is known that phenolic compounds in plants are rarely found in the free state. Most of them are presented in the form of various $\mathrm{O}$ - and $\mathrm{C}$-glycosides. The diversity of flavonoid glycosides is due to a significant amount of sugars and the different positions of their attachment to the aglycones, as well as the fact that sugars may have different configurations of glycosidic bonds.

It was identified the luksosa, beta-dl-arabinopyranose, sucrose, raffinose, glycerol, xylitol in the fenugreek leaves extracts. The presence of amino acids such as L-alanine, L-valine, L-proline, Lthreonine had been proved in these leaves. The oxyacetic, succinic, 2,3-dioxypropanoic, 2,3,4- threehydroxybutyric acids and fatty palmitic and alpha-linolenic acids were also identified in the leaves extracts.

Fenugreek essential oil contains: hexadecene, eicozanol, ethyl palmitate, ethylinoleate, beta-hydroxy-butyric,beta-aminoizobutyric, hydroxybutanedicarbonic, 1,2,3-propanethreecarbonic acids; ethyl esters of linoleic, levulinic, palmitic, ethylpalmitic, citric acids, which are likely to form a flavor of spicy-aromatic raw materials.

Conclusions. The presence of phenolic compounds, essential nutrients, aromatics in the fenugreek leaves should increase the shelf life, the nutritional value, improve the sensory properties of confectionery. 


\section{Introduction}

Food manufacturers, in particular confectionery products, are increasingly using spicearomatic plant raw materials as a source of biologically active substances (BAS). Essential oils, tannins and phenol substances play an important role in the formation of the flavor, promote the increase of the product shelf life. Besides, bioactive substances of medicinal plant can prevent cardiovascular diseases, carcinogenesis, inflammation, atherosclerosis and other human deseases $[1,2]$.

Leafy vegetable Fenugreek (Trigonella foenum-graecum) has been used as an effective medicinal plant as well as a fodder plant. Leaves of fenugreek hay have the aroma and antioxidant properties and pleasant taste [3-6]. It was shown that the green leaf of Trigonella foenum-graecum influenced the cholesterol balancing, sugar-level, skin inflammation (wounds, rashes, boils), treating arthritis, asthma, sore throat [9]. It was suggested that phytoconstituents such as flavonoids, alkaloids, terpenoids, steroids, saponins, anthocyanin, tannin and other were involved in this effect.

Fenugreek is an annual spice-aromatic plant, belongs to the legumes family. Seeds and leaves of plants contain many antiseptic, antioxidant and anti-inflammatory substances, such as apigenin, genistein, campeferol, quercetin, rutin, selenium, trihonellin alkaloid, iodine and are using in the food industry $[7,8]$. The foliage contain a large amount of bioactive substances: vitamins A, C, B1, B2, B9 (folic acid), nicotinic acid (vitamin PP), rutin, tannins, food fibers, macro and microelements - iron, potassium, phosphorus, magnesium, calcium etc. [10-14].

Phenolic compounds present in plants are rarely found in a free state. Most of them are presented in the form of various O- and C-glycosides. The variety of flavonoid glycosides is due to a significant amount of sugars (glucose, arabinose, xylose, etc.) and the their ability to attach to the position of aglycones, as well as sugars can have different configurations of glycoside bonds. To the best of our knowledge, there were not sufficient data on the composition of carbohydrates, amino acids, fatty acids, aromatic substances of fenugreek hay leaves in the scientific literature, and this substantiates the actuality of the present work.

Consequently, the identification and quantification of phenolic compounds in plant material requires complex researches.

The purpose of this work was to study the chemical composition of the leaves of fenugreek hay, the possibility of its use in the production of a new range of flour confectionery products with high fat content, in particular, crackers and puffy cookies, as a natural antioxidant and a flavoring additive. The presence of antioxidants in the formulation of foods with fat content is very important because they can inhibit the rate of fat oxidation [15]. To determine the classes of organic substances of fenugreek leaves the highperformance liquid chromatography was used.

\section{Materials and methods}

The samples of fenugreek (Trigonella foenum-graecum) leaves have been received from M.M. Grishko National Botanical Garden of National Academy of Sciences of Ukraine. 


\section{Ethanol extract obtaining}

$2.5 \mathrm{~g}$ of dry crushed leaf was putted to a $100 \mathrm{ml}$ flask, $60 \mathrm{ml}$ of $96 \%$ ethanol was added, reversed condenser was attached and flask was heating in a boiling water bath for $90 \mathrm{~min}$. After that, the water bath was cooled, the fridge was washed with $5 \mathrm{ml}$ of ethyl alcohol, and the content of the flask was filtered into a $100 \mathrm{ml}$ measuring flask. Then procedure was repeated with $35 \mathrm{ml}$ of ethanol. The final volume of ethanol extract was adjusted to $100 \mathrm{ml}$.

\section{Obtaining of hydrolyzed extracts}

$0.4 \mathrm{~g}$ of dry crushed leaves were transferred to a $100 \mathrm{ml}$ flask attached by a reversed condenser, $20 \mathrm{ml}$ of ethyl alcohol, $20 \mathrm{ml}$ of distilled water and $10 \mathrm{ml}$ of concentrated hydrochloric acid were added. After attaching the flask to the reversed condenser the mixture was heated for 90 minutes in a boiling water bath. After that, the condenser was washed with $20 \mathrm{ml}$ of distilled water and flask was cooled. The content of the flask was transferred to a $100 \mathrm{ml}$ separate funnel through a paper filter, $25 \mathrm{~g}$ of sodium chloride was added and mixed thoroughly. The organic compounds were extracted with $30 \mathrm{ml}$ of ethyl acetate, the procedure was carried out in two consequent repetitions. After extracts drying with anhydrous sodium sulfate, the ethyl acetate was evaporated by vacuum. After evaporation the residue was dissolved in $50 \mathrm{ml}$ of ethanol.

\section{Ultra high-speed high performance liquid chromatography}

Ultra high-speed high performance liquid chromatography of leave extracts was carried out using HPLC (WATERS (USA), column ACQUITY UPLC ${ }^{8} \mathrm{BEHC}_{18}, 1,7 \mu \mathrm{m}, 50 \times 2,1$ $\mathrm{mm}$ ) with diode-matrix detection (PDA) and gradient changing of the mobile phase (acetonitrile-water) composition.

Organic substances with hydrogen mobile atoms in plants are present in conjugated form and to investigate their composition in forms of aglycones acidic hydrolysis was used. After hydrolysis aglycones were extracted by ethylacetate and extracts were used for chromatography. Composition of remaining ethanol extracts after removal of ethanol were also analyzed [10].

\section{Spectrophotometric analysis}

Spectrophotometric analysis of leave extracts was performed on the spectrophotometer Specord 210 Plus (Germany) [16].

\section{Gas chromatography with mass-selective detection}

To identify component composition of the extracts, the derivatization method was used, which allows to increase the molecular weight of the initial substances. N-methyl-Ntrimethylsilyl-trifluoroacetamide (TMS) reagent was used for derivatization.

For TMS derivatives obtaining $5 \mathrm{ml}$ of ethanol extract was putted into vial and ethyl alcohol was removed by evaporation at $78^{\circ}$ C. $300 \mu \mathrm{g}$ of anhydrous pyridine and $100 \mu \mathrm{g}$ of TMS reagent were added to the dry residue. Vial was sealed and placed in UZB for 30 minutes. After this, $1 \mathrm{ml}$ of acetonitrite was added to the vial, mixed and obtained mixture of derivatives were analyzed on chromatograph Agilent GC/MSD 7890A/5975C with capillary column HP-5MS [13]. 


\section{Results and discussion}

According to electronic absorption spectrum of the samples the phenolic acids (absorption at $326 \mathrm{~nm}$ ), aromatic compounds (absorption in the range 350-600 nm), chlorophylls $(667 \mathrm{~nm})$ were presented in initial leaf extracts of fenugreek (Figure 1).

Displacement of the maxima to the ultraviolet region with an increase of the $\mathrm{pH}$ of the solution (Figure 1,2) indicates the destruction of the intramolecular hydrogen bond under $\mathrm{pH}$ increasing.

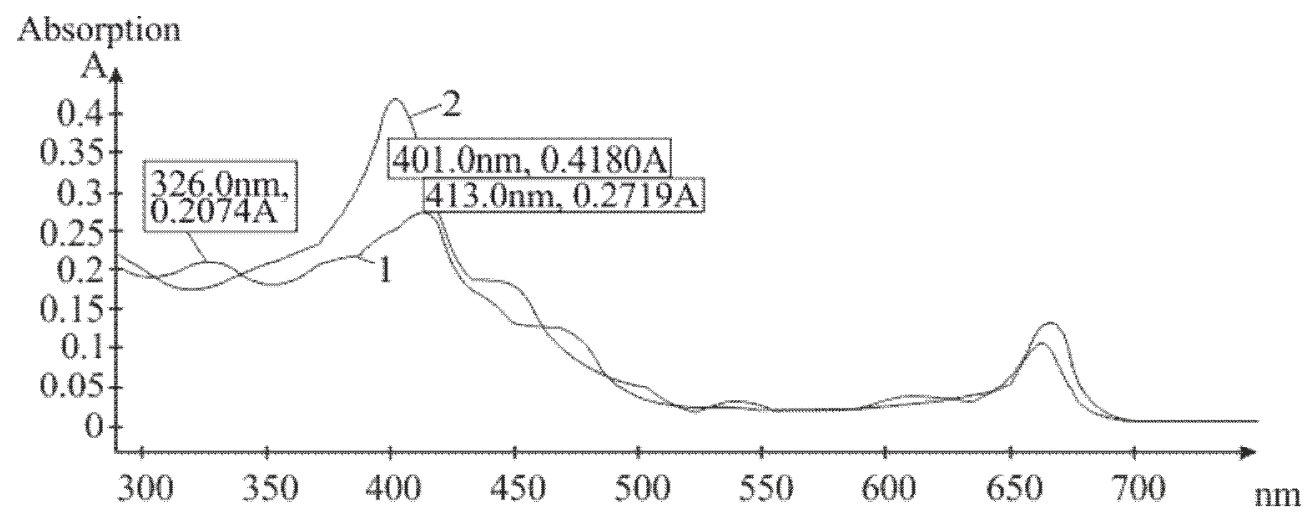

Figure 1. Electronic absorption spectrum of initial leaf extract $(1-\mathrm{pH}=6,5 ; 2-\mathrm{pH}=11,8)$

Ultra high-speed high performance liquid chromatography (UHPLC) of initial leave extracts (Figure 2a and $2 \mathrm{~b}$ ) have demonstrated presence of phenol carboxylic acids (retention time 4.52, 5.59, $6.46 \mathrm{~min}$ ), catechins (retention time 5.24, $5.45 \mathrm{~min}$ ) and alkaloid trihonellin (retention time $6.29 \mathrm{~min}$ ). Eight different substances were identified by this analysis with spectrophotometrical detection at 325.0 and $350 \mathrm{~nm}$ (Table 1).

Content of substances in initial leaf extract according to Figure 2 a, b

Table 1

\begin{tabular}{|c|c|c|c|}
\hline $\begin{array}{c}\text { Retention time, } \\
\text { min }\end{array}$ & $\begin{array}{c}\text { \% from the total } \\
\text { content }\end{array}$ & $\begin{array}{c}\text { Retention time, } \\
\text { min }\end{array}$ & $\begin{array}{c}\text { \% from the total } \\
\text { content }\end{array}$ \\
\hline \multicolumn{2}{|c|}{ PDA 325.0 nm } & \multicolumn{2}{|c|}{ PDA 350.0 nm } \\
\hline 0,983 & 7,7 & 5,241 & 4,8 \\
\hline 4,520 & 54,9 & 5,454 & 17,3 \\
\hline 6,461 & 37,5 & 5,585 & 47,0 \\
\hline- & - & 5,830 & 18,0 \\
\hline- & - & 6,292 & 13,0 \\
\hline
\end{tabular}




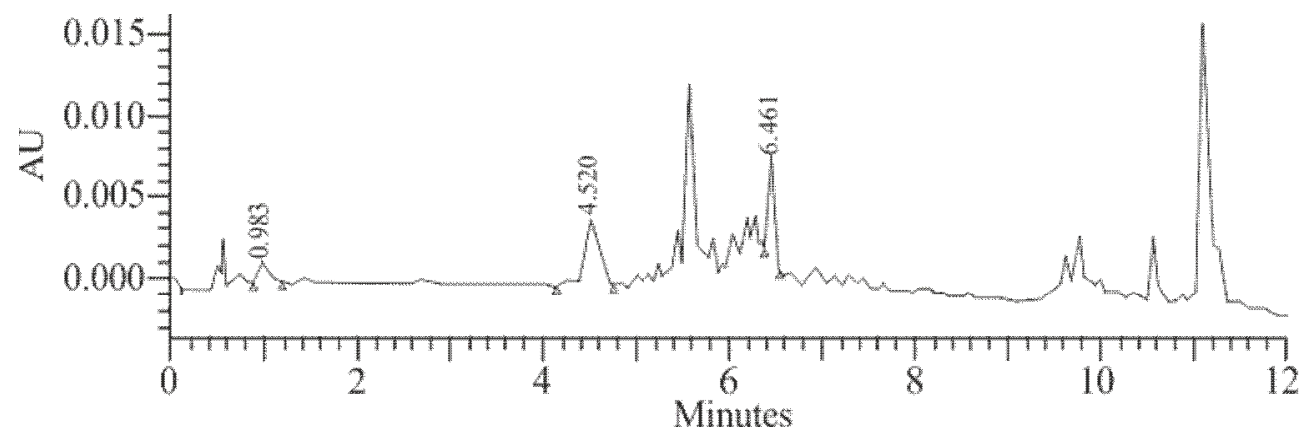

Figure 2a. Chromatogram of initial leaf extract (PDA 325.0 nm).

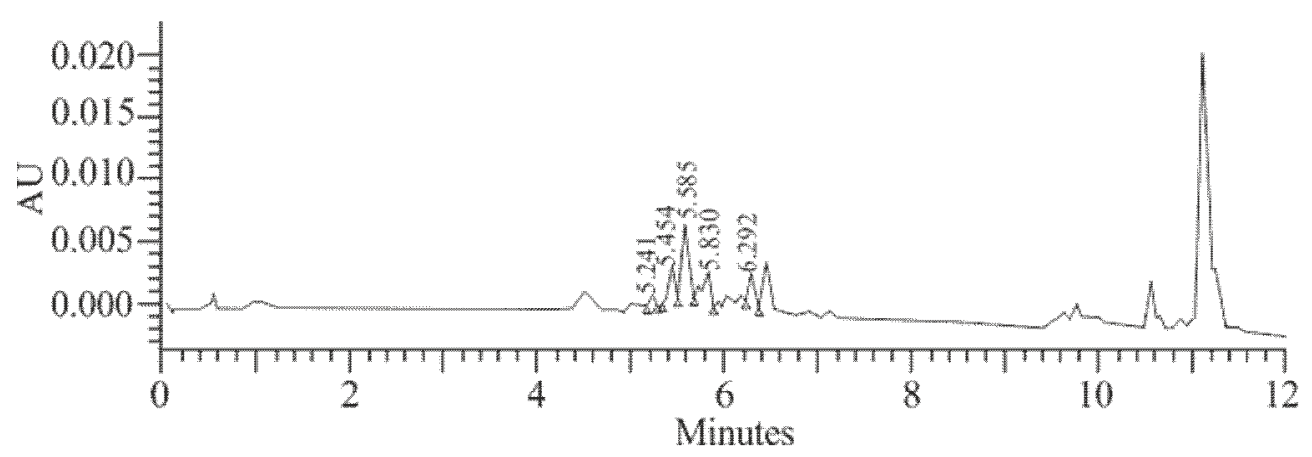

Figure 2b. Chromatogram of initial leaf extract (PDA 350.0 nm).

The distribution of peaks and their absolute intensity on the sample electronic absorption spectrum after acid hydrolysis were similar to the original spectrum (Figure 3).

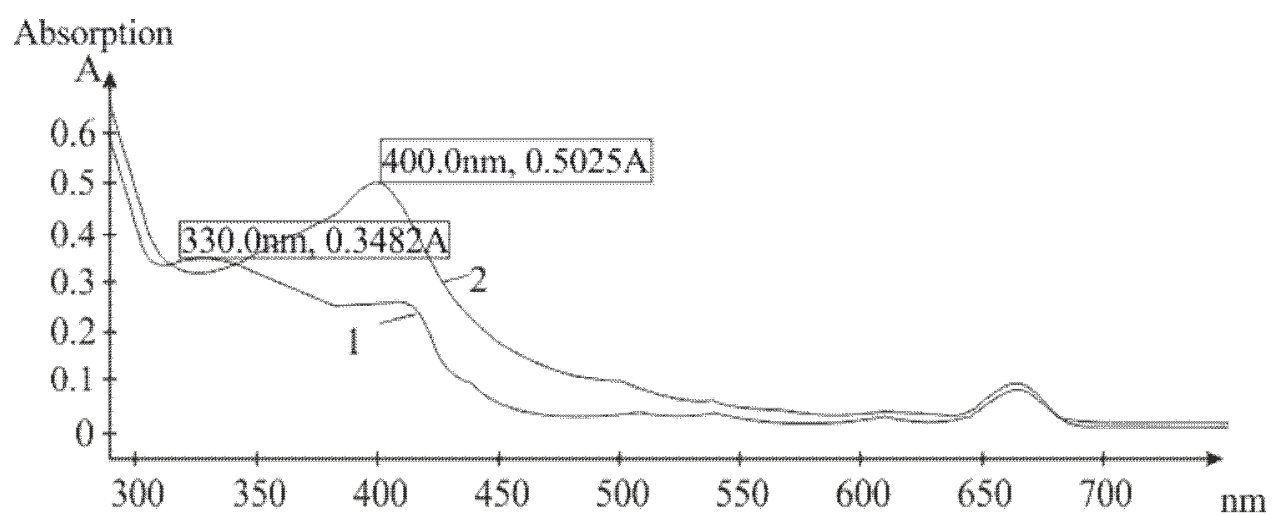

Figure 3. Electronic absorption spectrum of ethylacetate extracts after hydrolysis of leaf extracts $(1-\mathrm{pH}=6,5 ; 2-\mathrm{pH}=11,8)$ 
Analysis of this extracts by HPLC had shown that catechins were destructed under acid hydrolysis of initial leaf extract (Figure 4). Trihonellin was absent in ethylacetate extracts of hydrolyzed initial leaf extracts. The number of new substances were detected after acid hydrolysis, absorbtion peaks of which are close to phenolic acids. Ratio of detected components are presented in Table 2.

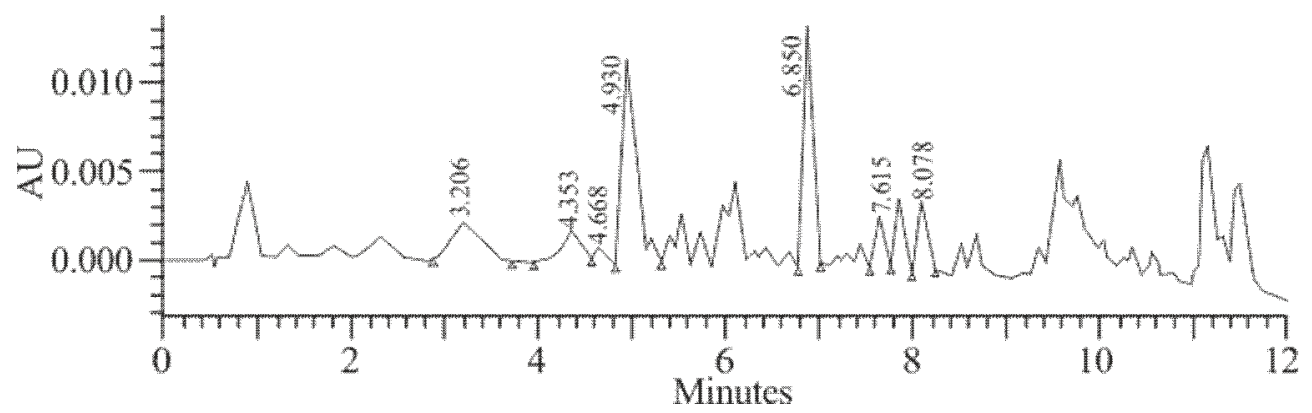

Figure 4. Chromatogramm of ethylacetate extracts after hydrolysis of leaf extracts (PDA 350)

Table 2

Ratio of components ethylacetate extracts after hydrolysis of leaf extracts (PDA $350.0 \mathrm{~nm}$ )

\begin{tabular}{|c|c|c|}
\hline № & Retention time, min & $\begin{array}{c}\text { \% from the total } \\
\text { content }\end{array}$ \\
\hline 1 & 3,206 & 14,84 \\
\hline 2 & 4,353 & 6,65 \\
\hline 3 & 4,668 & 1,30 \\
\hline 4 & 4,930 & 36,90 \\
\hline 5 & 6,859 & 25,02 \\
\hline 6 & 7,615 & 5,66 \\
\hline 7 & 8,078 & 9,63 \\
\hline
\end{tabular}

Using of mass-chromatography for analysis of initial leaf extracts gave possibility to detect number of aliphatic substances mainly hexadecen, linolenic acid and eycosanol (Figure 5).

The mass-chromatogramm of ethylacetate extracts after hydrolysis of leave extracts presented in Figure 6 have demostrated that after acid hydrolysis, a number of compounds appeared: ethyl esters of levulinic acid, ethyl palmitate, ethylinoleate.

The mass-chromatography of ethylacetate extracts after hydrolysis has detected the carbonic acid esters, that are probably the constituent of essential oil of fenugreek. They are the ethyl esters of levulinic acid, ethyl esters of citric acid, 1,2,3-propanetricarboxylic acid ethyl esters, ethyl esters of palmitic, linoleic, beta-hydroxy-butyric and citric acid. 

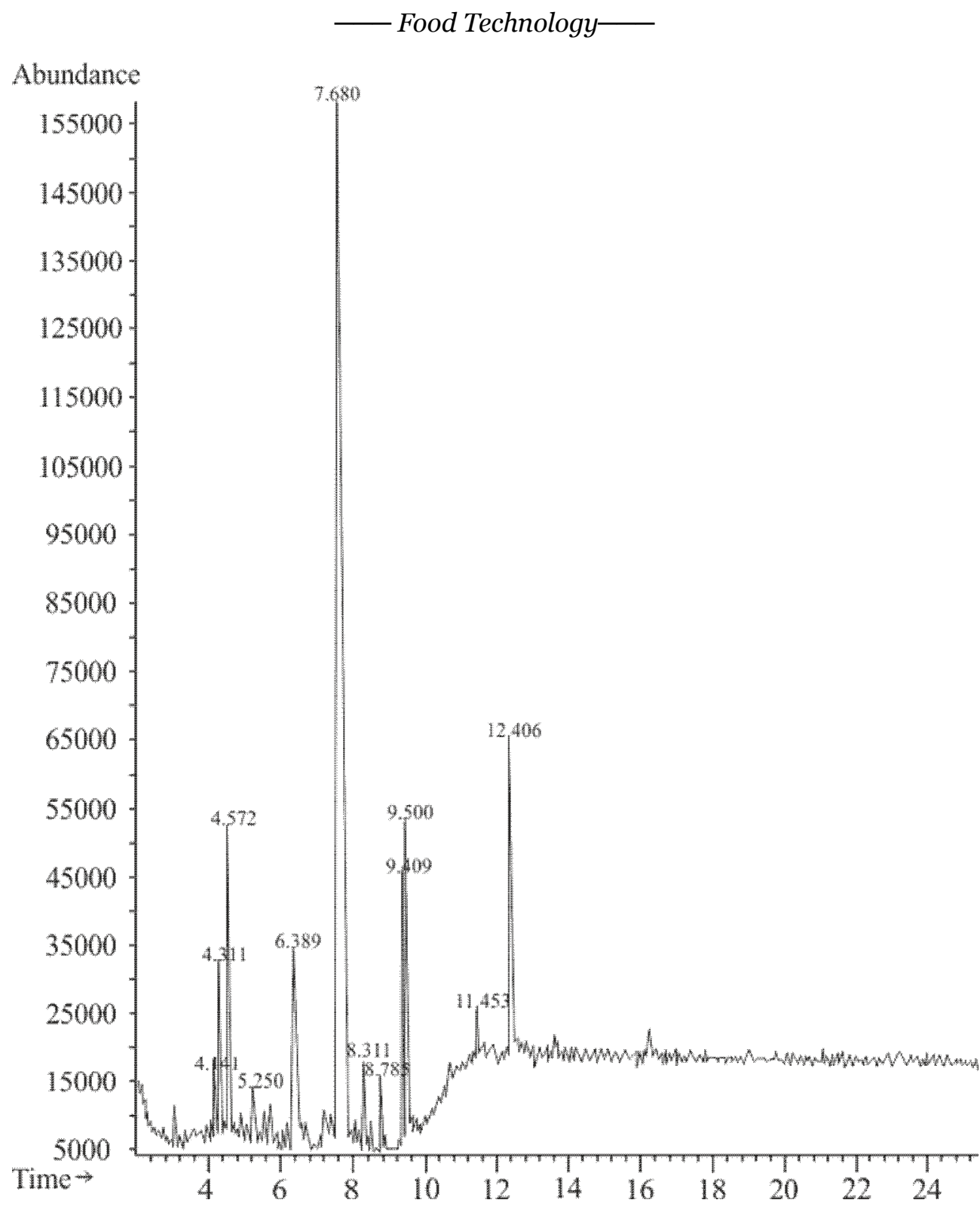

Figure 5. Mass-chromatogramm of initial fenugreek leaf extracts 


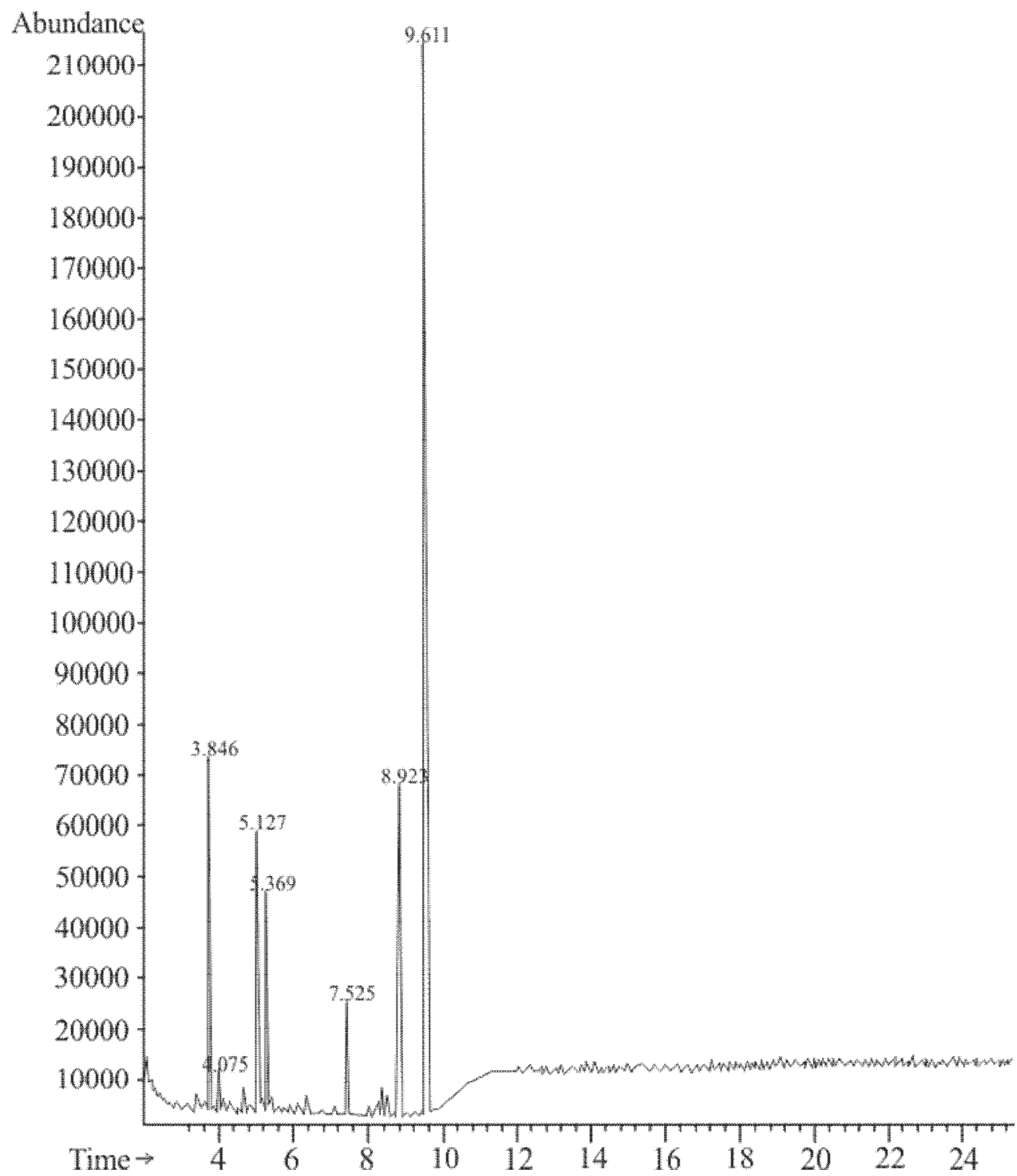

Figure 6. Mass-chromatogramm of ethylacetate extracts after hydrolysis of fenugreek leaf extracts

To identify component with low molecular weight derivatization method was used and amino acids L-alanine, L-valine, L-proline, L-threonine, a number of carbohydrates, mainly lyksosa, $\beta$-dl-arabinopyranose, sucrose and raffinnose were detected in initial fenugreek leaf extracts (Figure7). The oxoacetic acid, succinic acid, 2,3-dioxypropane acid, 2,3,4 trihydroxybutyric acid, palmitic acid, $\alpha$-linolenic acid, as well as glycerol and xylitol were identified in these extracts after derivatization. 
Abundance

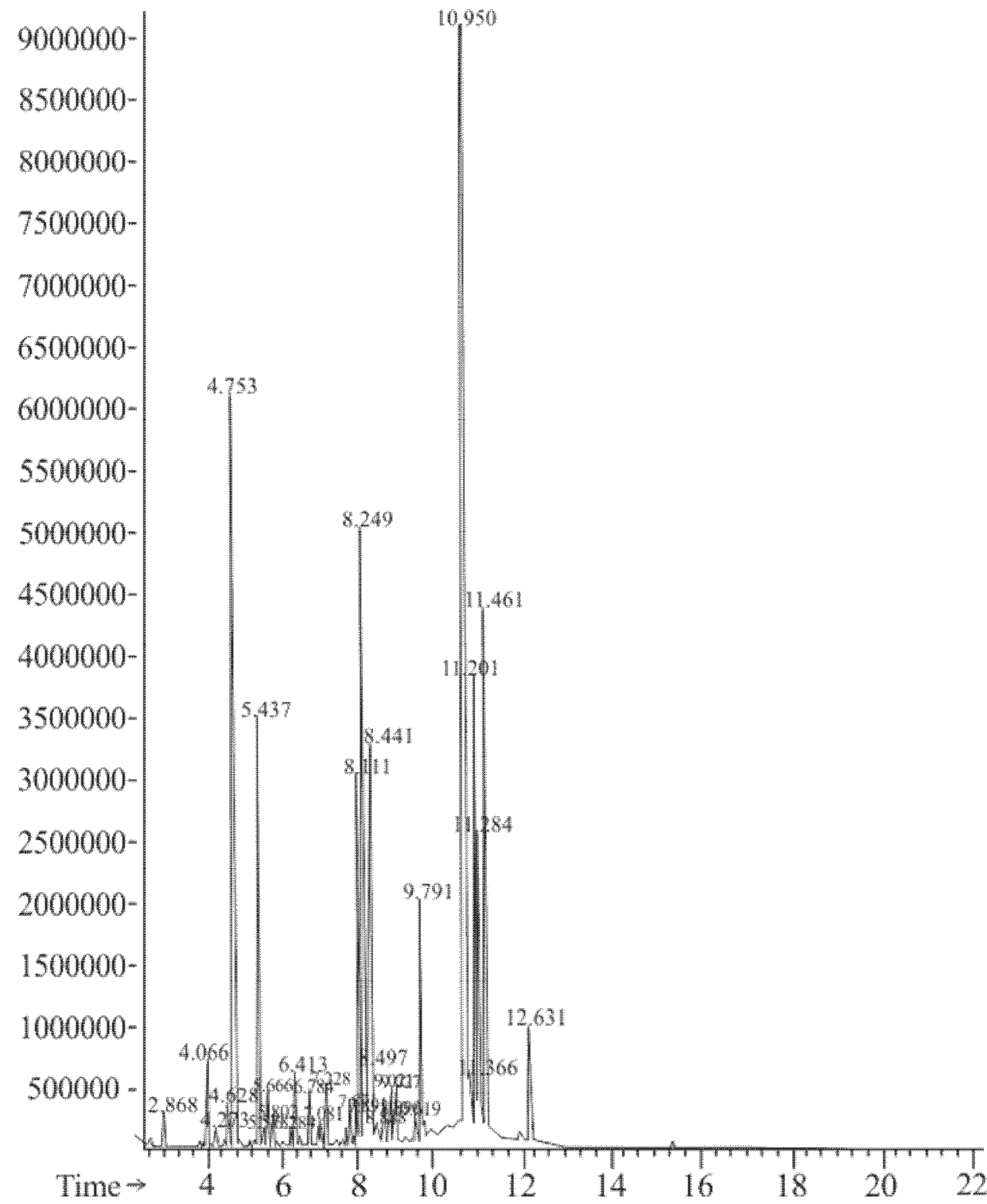

Figure 7. Mass-chromatogramm of TMS derivates of initial ethanol extracts of fenugreek leaf

The TMS derivates of constituents of fenugreek leaf extracts were obtained also after acidic hydrolysis. Mass-chromatogramm of TMS derivates of fenugreek leaf extracts after acidic hydrolysis have demonstrated presence of $\beta$-hydroxybutyric acid, betaaminoisobutyric acid, hydroxybutanedicarboxylic acid, citric acid, ethyl ester of palmitic 
and linoleic acid (Figure 8). The intense $(2,499 \mathrm{~min})$ peak is due to the interaction of the destruction product of the reagent (methylamine) with the reagent.

Therefore, using ultra high-speed high performance liquid chromatography, spectrophotometry, gas chromatography with mass-selective detection it was shown the presence of phenolic carboxylic acids, flavonoid compounds, trihonellin alkaloids, which have a high antioxidant potential, the components of fenugreek essential oils, sugars, amino acids and aromatic substances in fenugreek leaf.

Abundance

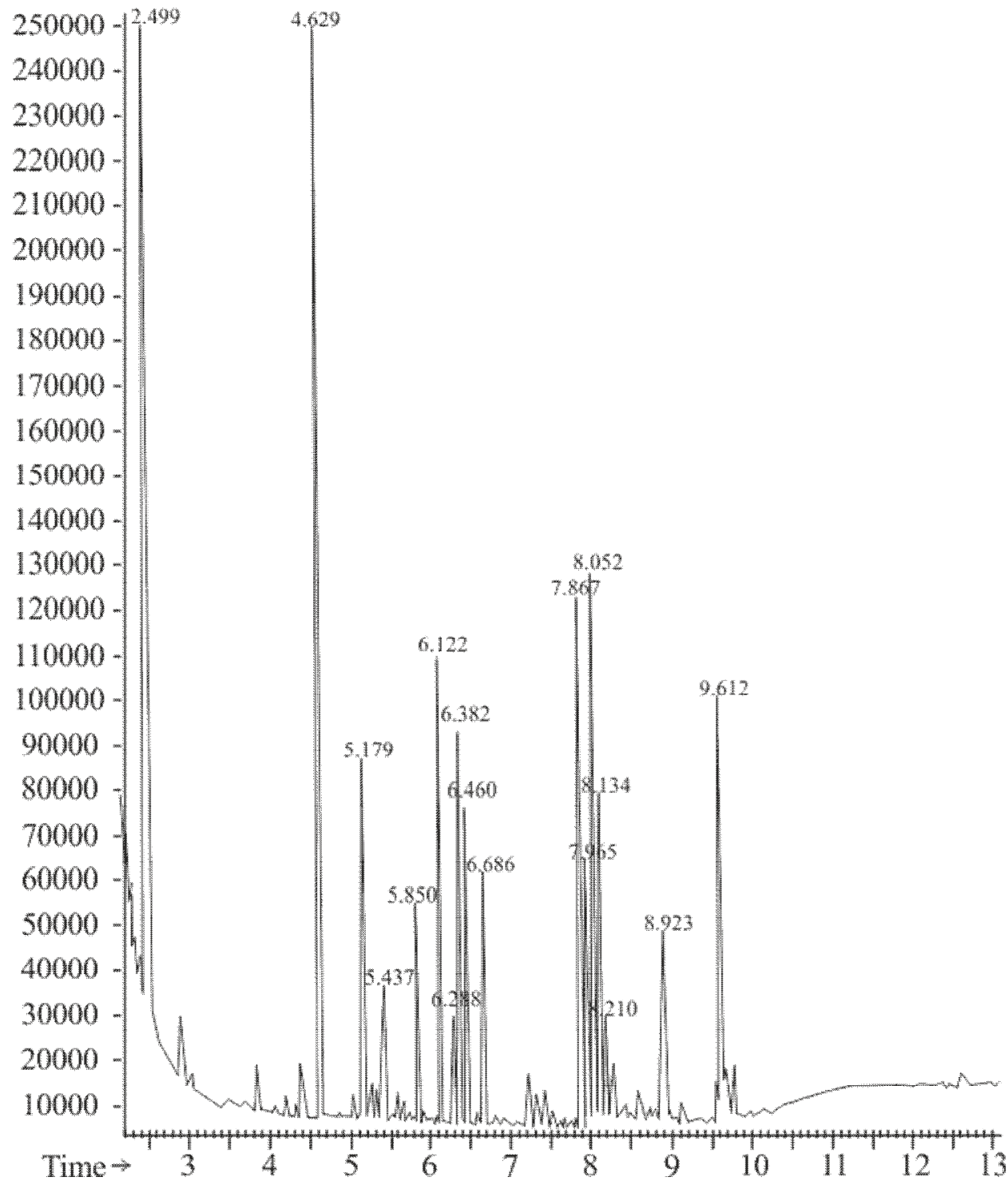

Figure 8. Mass-chromatogramm of TMS derivates of fenugreek leaf extracts after acidic hydrolysis 


\section{Conclusion}

1. For the first time by application of spectrophotometry method with reference to electronic absorption spectrum we were able to identify the phenolic acids (absorption at $326 \mathrm{~nm}$ ), aromatic compounds (absorption in the range 350-600 nm), chlorophylls (667 $\mathrm{nm}$ ) in initial leaf extracts of fenugreek.

2. By conducting analysis of this extracts by HPLC it was shown destruction of catechins and absent of trihonellin in ethylacetate extracts. New identified substances judging from absorption peaks are close to phenolic acids.

3. Mass-chromatography allowed us to recognize in fenugreek leaf extracts after acid hydrolysis a number of compounds: ethyl esters of levulinic acid, ethyl palmitate, ethylinoleate. However, alongside we found carbonic acid esters, that probably corresponds as constituent of essential oil of fenugreek. In addition we found number of carbohydrates and complex phenolic carboxylic acids, flavonoid compounds, trihonellin alkaloids, which have a high antioxidant potential. It is recommended the using of fenugreek leaf as effective source of antioxidants in production of the flour confectionery products, particularly of crackers and puffy cookies.

\section{References}

1. Srinivasan K. (2005), Role of spices beyond food flavouring: nutraceuticals with multiple health effects, Food Reviews International, 21, pp. 167-188.

2. Hossain M.B., Brunton N.P., Barry-Ryan C., Martin-Diana A.B., Wilkinson M. (2008), Antioxidant activity of spice extracts and phenolics comparison to synthetic antioxidants, Rasayan J. Chem., 1, pp. 751-756.

3. Korableva O.A., Rakhmetov D.B. (2012), Poleznye rasteniia $v$ Ukraine: ot introduktsii do ispolzovaniia: monografiia, Fitosotsiotsentr, Kyiv.

4. Korablyova O. (2001), Alternative aromatic plants in Ukraine: cultivation and utilization, Proceedings of the 50 Anniversary Conference "Crop science on the verge of the 21 century - opportunities and challenges», Prague, Czech Republic, pp. 126127.

5. Oseiko M., Ukrainets A., Shtepa S. (2005), Likarska roslynna syrovyna, zhurnal "Kharchova i pererobna promyslovist», 7, pp. 15-17.

6. Koche D., Shirsat R., Imran S., Bhadange D.G. (2010), Phytochemical screening of eight traditionally used etnomedicinal plants from akola district (MS) India, International Journal of Pharma and Bio Sciences, 1(4), pp. 253-256.

7. Burt S.A. (2004), Essential oils: their antibacterial properties and potential applications in foods: a revive, Intern. J. Food Microbiol, 94, pp. 223-253.

8. Rakhmetov D.B., Stadnichuk N.O., Korabljova O.A. (2004), Novi kormovi, prjanosmakovi ta ovochevi introducenty $v$ Lisostepu i Polissi Ukrajiny, Fitosociocentr, Kyiv.

9. Wan-Li X. (2007), Effect of Trigonella foenum-graecum (fenugreek) extract on blood glucose, blood lipid and hemorheological properties in streptozotocin-induced diabetic rats, Asia Pacific Journal of Clinical Nutrition, 16, pp. 422-426.

10. Omezzine F., Bouaziz M., Daami-Remadi M., Simmonds M.S., Haouala R. (2014), Chemical composition and antifungal activity of Trigonella foenum-graecum L. varied with plant ploidy level and developmental stage, Arabian Journal of Chemistry, pp. 111. 
11. Sumayya A.R., Srinivasan S., Amatullah N. (2012), Screening and Biochemical Quantification of Phytochemicals in Fenugreek (Trigonella foenum-graecum), Research Journal of Pharmacentical, Biological and Chemical Sciences, 3(1), pp. 165169.

12. Renuka C. (2009), Evaluation of the antidiabetic effect of Trigonella foenum-graecum seed powder on alloxaninduced diabetic albino rats, International Journal of Pharmaceutical and Technical Research, 1, pp. 1580-1584.

13. Kumaravel S., Muthukumaran P., Shanmugapriya K. (2017), Chemical composition of Trigonella foenum- graecum through gas chromatography mass spectrometry analysis, Journal of Medicinal Plants Studies, 5(3), pp. 1-3.

14. Landge D. (2005), From sauce to shelf an introduction to the supply chain of medicinal and aromatic plants, Abstract of XYII International Botanical Congress, Vienna, pp. $105-106$.

15. Pakhomova I. V. (2016), Antyoksydanty roslynoho pokhodzhennia dlia zhyrovmisnykh kondyterskykh vyrobiv, Naukovi pratsi NUKhT, 22(11), s. 185-190.

16. Moliner-Martinez Y., Campins-Falco P., Herraier - Hernoinder R. (2004), A method for the determination of dimethylamine in air by collection on solid support sorbent with subsequent derivatization and spectrophotometric analysis, J.Chromatogr.A., 1059, pp. 17-24. 